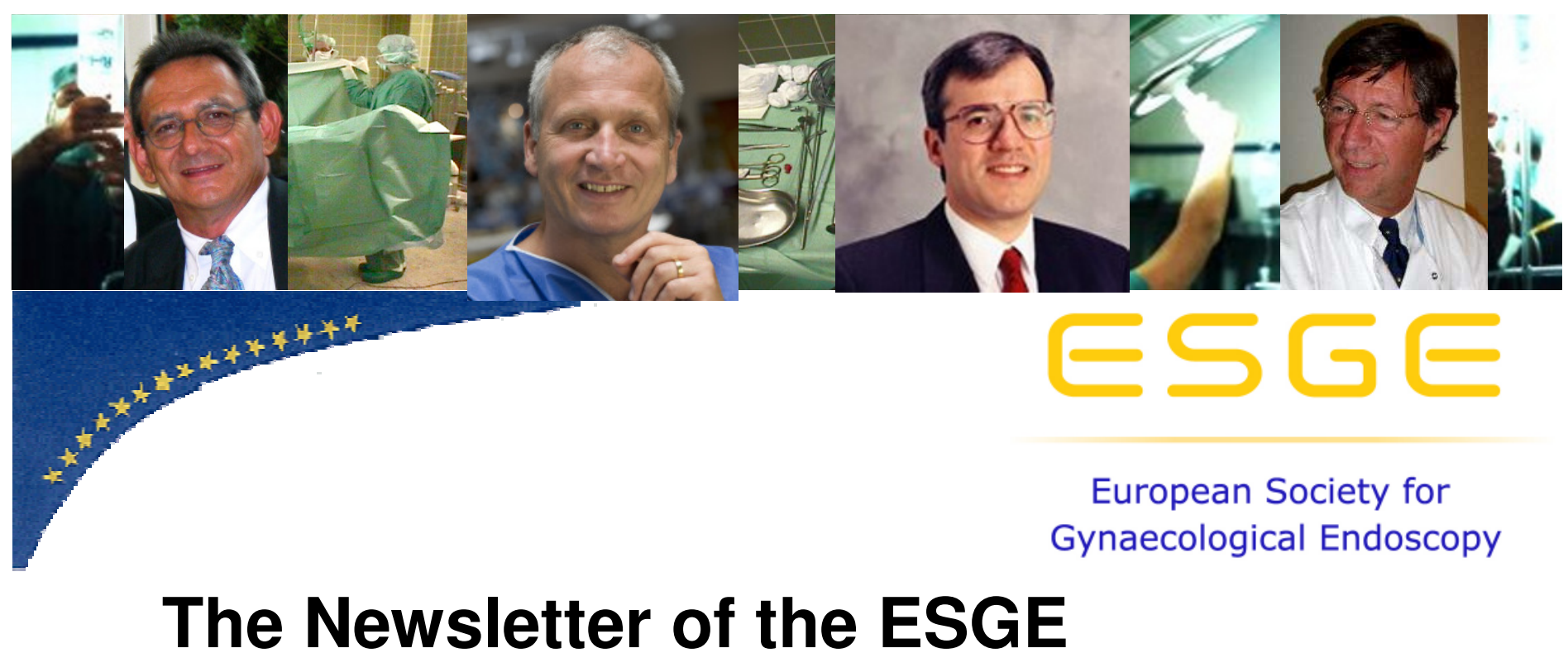

2nd edition 2010

Dear Colleagues,

If you are interested in the social life of the ESGE

please see: $w w w . e s g e . o r g / ? p=1 \& p 2=40 \& i d=80$ for the following topics:

1. Invitation to the 19th Annual Congress of the ESGE in Barcelona in 2010

Francisco Carmona Gilabert Aguilar

2. The Spanish Society of Gynaecologic Tirso Perez-Medina Endoscopy

3. Events in the ESGE and its Member Societies

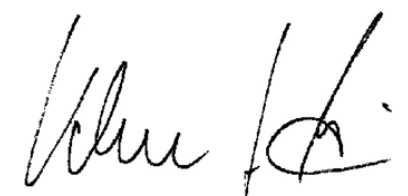

With best regards

Klaus J. Neis
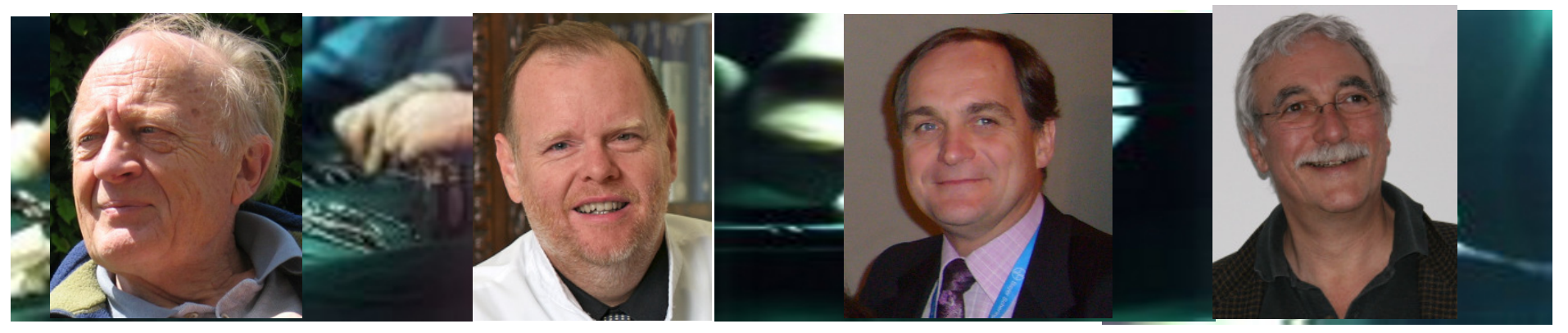


\section{ESGE membership form 2010}

Return the completed form by EMAIL to: centraloffice@esge.org or by FAX to: +3216629639 or by POST to: ESGE centraloffice (see address below).

\begin{tabular}{|l|l|l|l|}
\hline Personal details (Please click within each text-box) & Title & Date of birth \\
\hline First name & Last name & Telephone \\
\hline Hospital/Institution/Organisation & Department & Email address \\
\hline Address (street and $\mathrm{N}^{\circ}$ ) & & \\
\hline Postal code & City/Town & Country \\
& & \\
\hline
\end{tabular}

\begin{tabular}{|l|l|}
\hline Payment section & (Please tick the appropriate check-box) \\
\hline$\square 125$ & $\begin{array}{l}\text { Regular ESGE-membership. } \\
\text { Subscription to the Journal 'Gynecological Surgery' is included in the fee. }\end{array}$ \\
\hline$\square € 75$ & $\begin{array}{l}\text { Trainee or resident in Obs/Gyn (please prove by document). } \\
\text { Subscription to the Journal 'Gynecological Surgery' is included in the fee. }\end{array}$ \\
\hline
\end{tabular}

\begin{tabular}{|c|c|c|}
\hline \multicolumn{3}{|c|}{ Payment modalities (Please tick the appropriate check-box) } \\
\hline Bank transfer & \multicolumn{2}{|c|}{$\begin{array}{l}\text { I will make a bank transfer in EURO to the ESGE } \\
\text { IBAN: BE74 } 310126334607 \\
\text { SWIFT code: BBRUBEBB } \\
\text { Bank address: ING Belgium, Grote Markt 5, } 3200 \text { Aarschot, Belgium. } \\
\text { No costs for the beneficiary. }\end{array}$} \\
\hline \multirow{3}{*}{$\begin{array}{l}\text { Charge my creditcard } \\
\text { (Visa/Mastercard) }\end{array}$} & \multicolumn{2}{|c|}{ Card Number } \\
\hline & Expiry date & CVC code (last 3 digits at backside) \\
\hline & \multicolumn{2}{|c|}{ Name of cardholder } \\
\hline
\end{tabular}

Signature:

Place:

Date:

\section{Confirmation of payment will be emailed to you. If you do not receive this email please contact the centraloffice.}

ESGE Central Office p/a ID Trust Medical

Ms Katrien Goeminne and Ms Kristien Carmeliet

Diestsevest 43

3000 Leuven, Belgium
Tel. +32 (0)16 629629

Fax. +32 (0)16 629639

Email: centraloffice@esge.org 